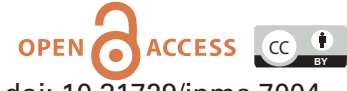

doi: $10.31729 /$ jnma.7004

\title{
The Yentl Syndrome: A Case Report
}

\author{
Barkadin Khan, ${ }^{1}$ Anjan Kumar Basnet ${ }^{2}$ \\ 'Shahid Gangalal National Heart Center, Kathmandu, Nepal, ${ }^{2}$ Health Foundation Nepal, Lalitpur, Nepal.
}

\section{ABSTRACT}

Cardiovascular disease, including ischemic heart disease, is one of the most common causes of death and disability in both sexes. The traditional concept of ischemic heart disease as a "man's disease" is debunked. Yentl syndrome is used to describe the underdiagnosis of ischemic heart disease in females and its associated effects. This article reports a 48 -year-old female presented to the emergency department with acute epigastric discomfort. Her initial diagnostic tests did not reveal any abnormalities, and she was discharged. Subsequently, after four days, she again visited the emergency department with chest pain, the evaluation of which furthermore revealed no abnormalities. However, we admitted her. After 40 hours of hospitalization, her evaluation revealed anterior wall ST elevation myocardial infarction, and she underwent emergent reperfusion via coronary catheterization. This combination of atypical signs and symptoms and chances of delayed manifestations in the diagnostic investigations provides evidence for a need for thorough assessment in a female with chest pain.

Keywords: cardiovascular disease; case report; women.

\section{INTRODUCTION}

Females represent nearly half of total deaths from cardiovascular (CVD). ${ }^{1}$ CVD in women; however, may go unrecognized, particularly at younger ages, as they are more likely than men to present atypical symptoms such as abdominal discomfort, fatigue, sleep disturbance, shortness of breath, weakness, indigestion, and anxiety. ${ }^{2}$ Endothelial dysfunction, small vessel size, and diffuse atherosclerosis are the causes of ischemia without evidence of a blockage..$^{3-4}$ We report a female patient diagnosed with ischemic heart disease after two days of admission despite having normal investigations in the initial workup.

\section{CASE REPORT}

The patient is a 48-year-old female with no risk factors of atherosclerosis causation presented to the emergency department (ED) of Shahid Gangalal National Heart Center with complaints of epigastric pain for the past four days. She described the pain as mid-sternal, continuous, radiating towards the left arm, and associated with sweating but not related to exertion. She could not recall the pain in the past and denied tobacco smoking, alcohol intake, or illicit drug abuse. She also does not have any family history of coronary artery disease or premature deaths.
Upon presentation to the ED, her initial vitals were: blood pressure 170/110 mm Hg, pulse 101 beats/min, regularly regular, temperature $97.5^{\circ} \mathrm{F}$, respiratory rate 20 breaths $/ \mathrm{min}$, and oxygen saturation $96 \%$ in the room air. Her cardiac evaluation was stable without any murmurs or rubs, and respiratory examination revealed bilaterally clear lungs with normal breath sounds. Her initial 12-lead electrocardiogram (ECG) demonstrated normal sinus rhythm with mild tachycardia (107 beats/min), normal axis, and no ST or T waves deviations (Figure 1). Her screening echocardiography and cardiac biomarkers also did not reveal any abnormalities. In ED, she was managed with intravenous antihypertensive and antacid. Her pain subsided on its own without the administration of nitrates or morphine. She was admitted to the cardiology department to evaluate her chest pain and started treatment with aspirin, statin, beta-blocker, ACE inhibitor before a planned coronary angiography after 72 hours. During the hospital stay, the etiological investigations such as fasting blood glucose level, lipid profile, renal function test, complete blood count did

Correspondence: Dr. Anjan Kumar Basnet, Health Foundation Nepal, Lalitpur, Nepal. Email: chhetri.title.ab@ gmail.com, Phone: +977-9849055133. 
not reveal any risk factors for coronary artery disease.

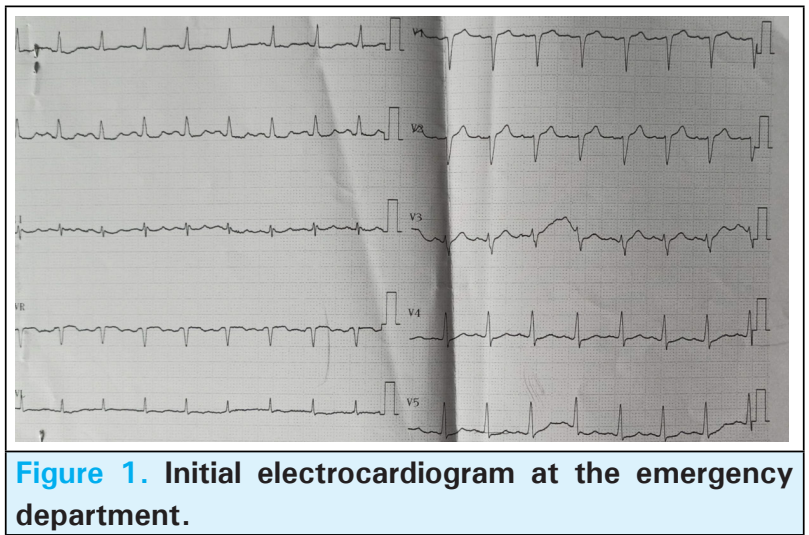

After 40 hours of admission, she again complained of retrosternal chest pain, a severe tearing type associated with sweating and nausea. The pain lasted for 30 minutes. ECG performed revealed significant ST elevation in leads V1, V2, V3, V4, and ST depression in leads II, III, and aVF (Figure 2). Screening echocardiography showed hypokinetic left anterior descending artery territory, mild mitral regurgitation, and left ventricular ejection fraction (LVEF) of $40 \%$. Coronary angiography performed stat revealed significant occlusion in the ostial left anterior descending (LAD) artery while the right system was normal (Figure 3).
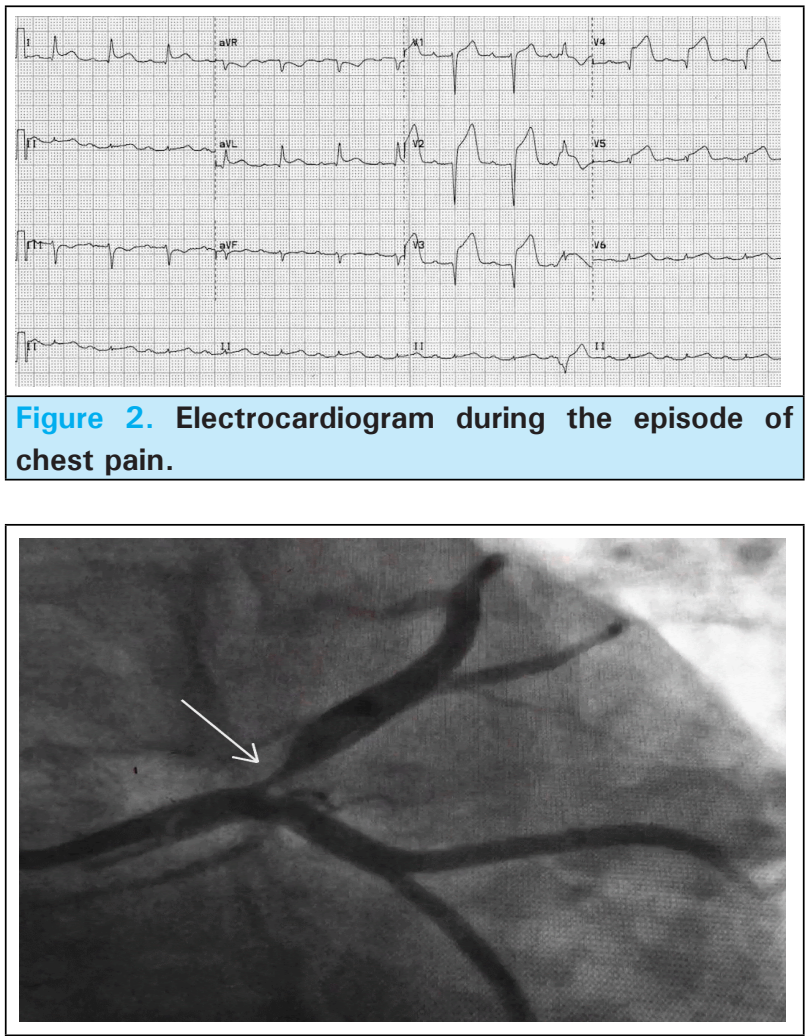

Figure 3. Coronary Angiography Right Anterior Oblique caudal view shows significant occlusion of ostial LAD artery.
The cardiac catheterization team was notified and mobilized for the preparation of percutaneous coronary intervention ( $\mathrm{PCl}$ ). Emergent rescue $\mathrm{PCl}$ with drug-Eluting stent implantation was performed via the right radial approach. Complications like slow flow or no-reflow were not observed, and thrombolysis in myocardial infarction (TIMI) 3 flow was restored. The patient was transferred to the intensive care unit (ICU) for further management, where she reported improvement in chest pain. The ECG changes improved within a few hours of the procedure. The patient was stepped down to the ward after 48 hours of ICU stay and then discharged after three days of stay in the ward.

On six months of follow-up following discharge, she expressed good exercise tolerance with no chest pain, and her vitals were within the normal range. ECG revealed no new changes, and echocardiography showed mildly hypokinetic anterior wall and improved LVEF of about $50 \%$.

\section{DISCUSSION}

The literature suggests that when women present like men (with 'male-pattern obstructive CHD), they are more likely to be assessed and treated like men. As characterized by the 'Yentl syndrome' depicted in the Barbra Streisand movie of the same name, Dr. Bernadine Healy described this term in 2001 to call attention to the paradox of adverse outcomes of women with ischemic heart disease (IHD), as well as the under-diagnosis and under-treatment of women. ${ }^{5}$ The harmful ischemic heart disease gender gap is widest in relatively young women, where MI mortality is twofold higher in women younger than 50 years compared with age-matched men.

Perhaps the most significant contributor to this is that their doctors simply miss their diagnosis. It is partly because women often don't have the "Hollywood heart attack" with chest and left-arm pains. Women, mainly young, may present without any chest pain but stomach ache, breathlessness, nausea, and fatigue. These symptoms, often described as "atypical," may lead to the under-appreciation of risk associated. ${ }^{2}$ Similar situation occurred with our patient, who visited ED initially for epigastric pain. As she did not have a typical presentation of Acute Coronary Syndrome (ACS) and her evaluation, such as ECG and cardiac markers, also did not reveal any abnormalities, so she was discharged with a provisional diagnosis of anxiety. But on a subsequent visit to ED for chest pain with left arm radiation, we admitted her to our cardiology department to further evaluate her chest pain, and we discovered the unexpected outcome as a left ostial LAD occlusion ST-segment myocardial 
infarction.

Studies have demonstrated under-treatment of women with medication, including lower rates of aspirin and ACE inhibitor use in stable women than men, lower rates of ACE inhibitor, beta-blockers, and statins in ACS women than men. ${ }^{6}$ ACS women undergo fewer index angiograms, percutaneous coronary interventions, and coronary artery bypass grafting (CABG) than their male counterparts. ${ }^{7}$ Atherosclerotic plaque in women is less fibrotic and contains more lipid-filled foam cells, owing to more significant potential for reversibility but potentially increasing vulnerability for rupture and thrombus formation. ${ }^{5-6}$ But women's symptom misinterpretation may lead to the wrong diagnosis and treatment with potentially unfavorable consequences. The presence of typical symptoms does not have any difference in the disease diagnosis between women and men..$^{8-9}$ However, when prodromal symptoms are recognized early in women, they have better survival than men. ${ }^{10}$ This case report presents an interesting case of missing CAD initially. Heightened attention in the evidence-based approach in diagnosing and managing $\mathrm{CHD}$ in females is recommended.

Consent: JNMA Case Report Consent Form was signed by the patient and the original article is attached with the patient's chart.

\section{Conflict of Interest: None.}

\section{REFERENCES}

1. American Heart Association. 2021 Heart Disease \& Stroke Statistical Update Fact Sheet Females \& Cardiovascular Diseases [Internet]. Dallas (TX): American Heart Association; 2021 [cited 2021 Jul 12]. Available from: https:/ / www.heart. org/-/media/phd-files-2/science-news/2/2021-heart-andstroke-stat-update/2021_stat_update_factsheet_females_ and_cvd.pdf?la=en. [Full Text]

2. DeVon HA, Ryan CJ, Ochs AL, Shapiro M. Symptoms across the continuum of acute coronary syndromes: differences between women and men. Am J Crit Care. 2008 Jan;17(1):14-24. [ubMed | Full Text | DOI]

3. Habib S. Coronary artery disease in women. Pakistan Heart Journal. 2011 Jan-Jun;44(1-2):18-26. [Full Text]

4. Bairey Merz CN, Shaw LJ, Reis SE, Bittner V, Kelsey SF, Olson M, et al. Insights from the NHLBI-Sponsored Women's Ischemia Syndrome Evaluation (WISE) Study: Part II: gender differences in presentation, diagnosis, and outcome with regard to gender-based pathophysiology of atherosclerosis and macrovascular and microvascular coronary disease. J Am Coll Cardiol. 2006 Feb 7;47(3 Suppl):S21-9. [ Full Text | DOI]

5. Healy B. The Yentl syndrome. N Engl J Med. 1991 Jul 25;325(4):274-6. [PubMed | Full Text | DOI]
6. Bugiardini R, Yan AT, Yan RT, Fitchett D, Langer A, Manfrini $\mathrm{O}$, et al. Factors influencing underutilization of evidence-based therapies in women. Eur Heart J. 2011 Jun;32(11):1337-44. [ PubMed | Full Text | DOI]

7. Johnston N, Schenck-Gustafsson K, Lagerqvist B. Are we using cardiovascular medications and coronary angiography appropriately in men and women with chest pain? Eur Heart J. 2011 Jun;32(11):1331-6. [PubMed | Full Text | DOI]

8. Vaina S, Milkas A, Crysohoou C, Stefanadis C. Coronary artery disease in women: From the yentl syndrome to contemporary treatment. World J Cardiol. 2015 Jan 26;7(1):10-8. [ubMed | Full Text | DOI]

9. Milner KA, Funk M, Arnold A, Vaccarino V. Typical symptoms are predictive of acute coronary syndromes in women. Am Heart J. 2002 Feb;143(2):283-8. [PubMed | Full $\underline{\text { Text }} \mid \underline{\text { DOI] }}$

10. Graham MM, Westerhout CM, Kaul P, Norris CM, Armstrong PW. Sex differences in patients seeking medical attention for prodromal symptoms before an acute coronary event. Am Heart J. 2008 Dec;156(6):1210-1216.e1. [PubMed | $\underline{\text { Full Text }} \mid \underline{\text { DOI] }}$

\section{The Author(s) 2018}

This work is licensed under a Creative Commons Attribution 4.0 International License. The images or other third party material in this article are included in the article's Creative Commons license, unless indicated otherwise in the credit line; if the material is not included under the Creative Commons license, users will need to obtain permission from the license holder to reproduce the material. To view a copy of this license, visit http://creativecommons.org/licenses/by/4.0/ 